\title{
Giant renal leiomyoma: a case report and brief review of the literature
}

\author{
Matei Andreoiu, MD; ${ }^{*}$ Darrel Drachenberg, $M D_{;}^{\dagger}$ Ross MacMahon, $\mathrm{MD}^{\dagger}$
}

\begin{abstract}
We report on a very large renal leiomyoma in a man presenting with a 1-year history of lower back and flank pain and a rapidly growing abdominal mass. Since a cystic renal cell carcinoma could not be ruled out, a postembolization right radical nephrectomy was performed. Diagnosis was confirmed by pathologic and histologic analysis. Renal leiomyomas are very rare benign tumours that are nearly indistinguishable from leiomyosarcoma or renal cell carcinoma preoperatively. This case represents the second largest such entity reported and demonstrates the limited ability of accurate diagnostic determination preoperatively, with pathologic examination and immune-histochemical staining postnephrectomy representing the only definitive means of diagnosis. A brief review of the literature and an outline of typical clinical and pathologic features of renal leiomyomas are also presented.
\end{abstract}

Can Urol Assoc J 2009;3(5):E58-E60

\section{Clinical presentation}

A previously healthy 53-year-old male initially presented with a prominent right abdominal mass of 3 months duration following ongoing progressive growth. Appearance of the mass was preceded by an onset of intermittent abdominal pain and back discomfort radiating down the ipsilateral leg a year prior to presentation. The patient also experienced anorexia and a sustained weight loss of $9.1 \mathrm{~kg}$.

Physical findings included a protuberant abdomen with a visibly bulging right-sided flank and abdominal mass and mild associated tenderness. The remainder of the exam was normal, with the exception of mild peripheral pedal edema.

\section{Investigations}

An ultrasound revealed a cystic mass within the right peritoneal cavity measuring $27.7 \times 21.6 \times 25.3 \mathrm{~cm}$. Chest $x$-ray was normal. Blood work demonstrated a mild increase in liver enzymes and erythrocyte sedimentation rate. The urinalysis was negative for hematuria or pyuria. A computed tomography $(\mathrm{CT})$ of the abdomen revealed an exophytic mass arising from the upper pole of the right kidney with peripheral enhancing nodularity and calcification (Fig. 1). The right kidney was markedly displaced anteroinferiorly, which resulted in compression of the biliary tree and a contra-lateral shift of major abdominal structures. Metastatic workup was negative. A differential diagnosis of cystic renal cell carcinoma versus retroperitoneal sarcoma was entertained.

\section{Treatment and pathology}

The patient underwent aortography followed by selective angiography. The right renal artery was found coursing to the left of the aorta and inferior to the left renal artery. Right renal embolization was followed by radical nephrectomy.

The specimen measured $30 \times 29 \times 27 \mathrm{~cm}$ and weighed $11.7 \mathrm{~kg}$. On sectioning, the specimen revealed whitish tissue with a whorled appearance and intermittent hemorrhagic areas (Fig. 2). Microscopically, a diagnosis of leiomyoma was determined.

\section{Discussion}

Leiomyomas are most commonly found at autopsy but can become symptomatic when they are large in size. There is a $4 \%$ to $5.5 \%$ prevalence based on autopsy findings. ${ }^{1,2}$ Twothirds of all leiomyomas occur in women. There also seems to be a greater prevalence in the Caucasian population, with approximately $65 \%$ to $70 \%$ of cases documented in that population. Although symptomatic cases are reported to be more common between the second and fifth decades of life, incidental lesions are more commonly found in an older age group. ${ }^{3,4}$ In a recent review of 1030 consecutive nephrectomies for renal tumours performed at the Brady Urological Institute over a 10-year period, renal leiomyomas were responsible for $1.5 \%$ of the benign lesions and $0.3 \%$ of all treated kidney tumours. ${ }^{5}$

The most common presenting symptoms in clinically evident cases are a palpable mass (57\%) and abdominal/flank pain $(53 \%)$, with a combined occurrence in approximately $33 \%$ of cases. Only $20 \%$ present with gross hematuria. ${ }^{6}$ 
Leiomyomas have been shown to affect both kidneys equally and $75 \%$ of reported cases involve the lower pole. ${ }^{3}$ The average size and weight have been found to be $12.3 \mathrm{~cm}$ and $1.84 \mathrm{~kg}$, respectively. The largest reported leiomyoma measured $57.5 \mathrm{~cm}$ in maximum diameter and weighed $37.2 \mathrm{~kg}$.

As categorized by Steiner and colleagues in 1990, there are 2 main groups of leiomyomas based on the setting of clinical diagnosis. ${ }^{3}$ (1) Most commonly, they are incidentally discovered during autopsy or surgery as multiple small cortical tumours less than $2 \mathrm{~cm}$ in size. (2) Rarely, however, they can also become large solitary masses that are incidentally found on imaging and can cause clinical symptoms secondary to their extreme size. ${ }^{3}$ Although not different histologically, the larger variant is usually associated with cystic degeneration and hemorrhage.

Leiomyomas can originate from smooth muscle cells in the renal capsule or renal pelvis or from the tunica media layer of the cortical vasculature. ${ }^{8,9}$ In a review by Steiner and colleagues, $53 \%$ of reported symptomatic lesions were of subcapsular origin, $37 \%$ were capsular and $10 \%$ were connected to the renal pelvis. ${ }^{3}$ Gross pathologic analysis usually reveals a well-encapsulated and sharply circumscribed mass that is more often solid than cystic. It is thought that cystic variants represent benign cystic degeneration. ${ }^{3,10,11}$ Leiomyomas tend to have a whorled appearance on cut section. On histologic analysis, unlike in leiomyosarcomas, the absence of mitotic figures, pleomorphism and hyperchromatism are the usual features. ${ }^{12,13}$ Importantly, any evidence of invasion usually indicates a malignant leiomyosarcoma. ${ }^{12-14}$

Diagnosis of a leiomyoma by imaging is unreliable. Ultrasound may display a solid or cystic mass and allow for identification of a plane between the tumour and kidney, but has very poor specificity. Angiographic appearance can be either hypo- or hyper-vascular $10,15,16$ and fea-

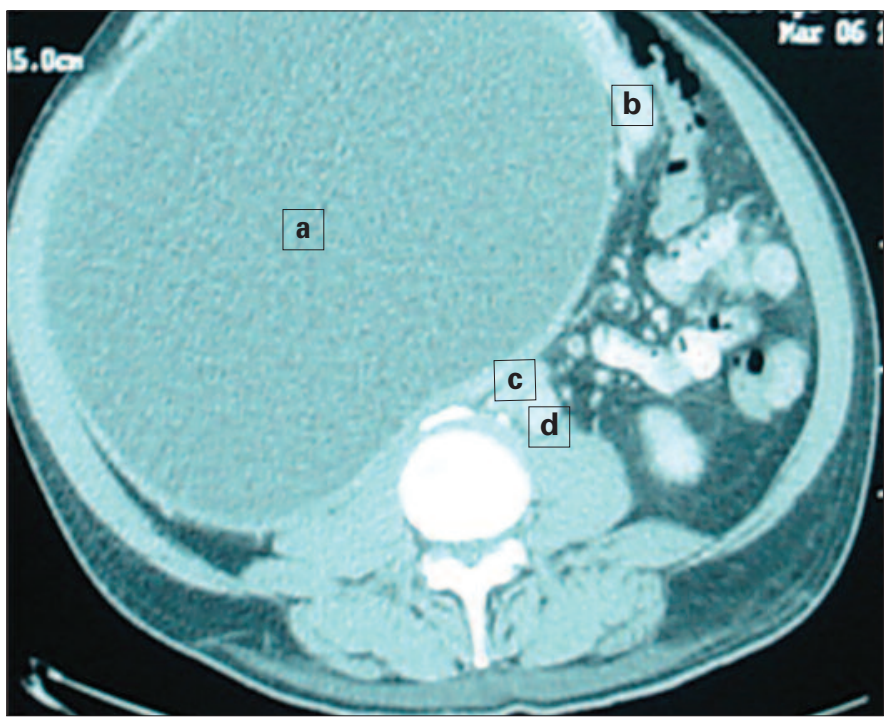

Fig. 1. CT image showing mass effect secondary to large right renal leiomyoma; (a) cystic leiomyoma; (b) left kidney (lower pole); (c) vena cava; (d) aorta. tures indicative of malignancy, such as vessel encasement, renal vein invasion or arteriovenous shunting, are absent. ${ }^{17}$ Computed tomography scanning provides improved anatomic definition and reveals well-circumscribed margins, a capsular/subcapsular or peripelvic origin, minimal parenchymal distortion, and no evidence of extra-renal invasion. ${ }^{3,16,18}$

Unlike benign leiomyomas, renal cell carcinomas have irregular, poorly defined margins and may invade adjacent structures. Differentiating leiomyoma from leiomyosarcoma is difficult unless the mass is clearly invasive on imaging. Both tend to develop in areas containing smooth muscle $\mathrm{e}^{19,20}$ and the size and weight are similar at presentation.7,14,15 It has been proposed that leiomyosarcomas represent a process of malignant degeneration from leiomyomas. ${ }^{10,12}$ No clear association between size and likelihood of sarcomatoid change has been demonstrated. ${ }^{15}$ However, weight loss and hematuria are more likely to be associated with leiomyosarcoma. ${ }^{14}$

Interestingly, in a case recently reported by a team at Johns Hopkins, a patient with benign leiomyoma was diagnosed preoperatively through image-guided core biopsy and immunostaining analysis. ${ }^{5}$ In cases where available clinical or radiographic evidence points away from renal cell carcinoma, this approach can be used to determine the exact diagnosis preoperatively and thereby spare the patient unnecessary radical surgery.

\section{Conclusion}

This case presents one of the largest leiomyomas reported in the literature. It highlights the tumour's potential for assuming extreme proportions and causing pronounced displacement of other major structures. It also re-emphasizes the difficulty of differentiating leiomyoma from renal cell carcinoma and leiomyosarcoma based strictly on clinical features and imaging. It is therefore advisable that surgical

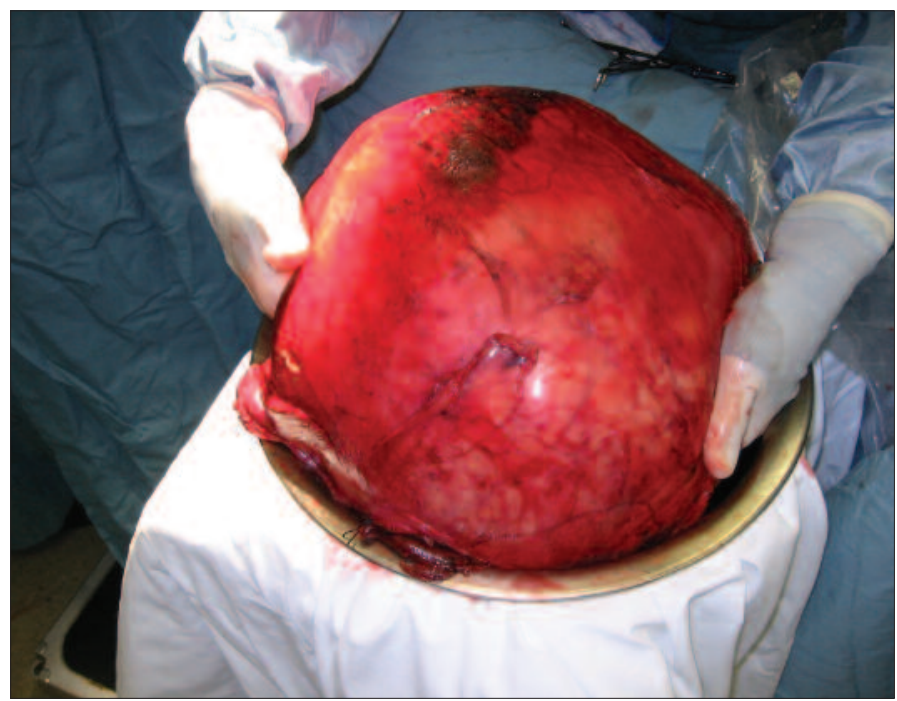

Fig. 2. Leiomyoma on display after removal from the patient. 
Andreoiu et al.

removal be performed for diagnostic and therapeutic purposes. Although nephron-sparing surgery can be performed for smaller or moderate-sized exophytic masses of apparent capsular or sub-capsular origin, radical nephrectomy remains the recommended treatment for large leiomyomas to avoid the risk of malignancy, necrosis and infection.

*Uro-Oncology Fellow, Department of Urology, University of Indiana, Indianapolis, IN; ${ }^{\dagger}$ Assistant Professor, Department of Urology, University of Manitoba, Winnipeg, MB

This paper has been peer-reviewed.

Competing interests: None declared.

\section{References}

1. Newcomb WD. The search for truth, with special reference to the frequency of gastric ulcer cancer and the origin of Grawitz tumours of the kidney. Proc Roy Soc Med 1937;30:113.

2. Xipell JM. The incidence of benign renal nodules (a clinicopathologic study). J Urol 1971;106:503-6.

3. Steiner $M$, Quinlan D, Goldman $S M$, et al. Leiomyoma of the kidney: presentation of 4 new cases and the role of computerized tomography. J Urol 1990;143:994-8.

4. Inoue $\mathrm{K}$, Tsukuda S, Kayano $\mathrm{H}$, et al. A case of hypervascular renal capsule leiomyoma. Radiat Med 2000;18:323-6.

5. Romero F, Kohanim S, Guilherme L, et al. Leiomyomas of the kidney: emphasis on conservative diagnosis and treatment. Urology 2005;66:1319.
6. Kho GT, Duggan MA. Bizarre leiomyoma of the renal pelvis with ultrastructural and immunohistochemical findings. J Urol 1989;141:928-9.

7. Clinton-Thomas CL. A giant leiomyoma of the kidney. Br I Surg 1956;43:497-501.

8. Nagar AM, Raut AA, Narlawar RS, et al. Giant renal capsular leiomyoma: study of two cases. Br J Rad 2004;77:957-8.

9. Lee SY, Hsu HH, Chang CT, et al. Renal capsular leiomyoma-imaging features on computed tomography and angiography. Nephrol Dial Transplant 2006;21:228-9.

10. Takezaki T, Nakama M, Ogawa A. Renal leiomyoma with extensive cystic degeneration. Urology 1985;25:401-3.

11. Bossart MI, Spiut HJ, Wright JE, et al. Multilocular cystic leiomyoma of the kidney. Ultrastructural Path 1982;3:367-74.

12. Gordon MP Jr., Kimmelstiel P, Cabell CL: Leiomyoma of the kidney. J Urol 1939;42:507.

13. Bennington JL, Beckwith JB. Tumors of the kidney, renal pelvis, and ureter. 1975. Washington D.C.: Armed Forces Institute of Pathology, $2^{\text {nd }}$ series, fasc. 12, p. 215.

14. Niceta P, Lavengood RW Jr., Fernandes $M$ et al. Leiomyosarcoma of kidney: review of the literature. Urology 1974;3:270-3.

15. Zollikofer $C$, Castaneda-Zuniga W, Nath HP, et al. The angiographic appearance of intrarenal leiomyoma. Radiology 1980;136:47-9.

16. Mohler JL, Casale AJ. Renal capsular leiomyoma. J Urol 1987;138:853-4.

17. Hayasaka K, Amoh K, Hashimoto H, et al. Evaluation of renal and perirenal leiomyoma on US, CT and angiography. Radiat Med 1993;11:81-5.

18. Selli C, Masi A, Vanni L. Conflicting aspects of renal leiomyoma with different imaging techniques. Urol Intern 1992;48:219-22

19. Dasgupta P, Sandison A, Parks C, et al. Case report: renal leiomyoma with unusual calcification. Clin Rad 1998:53:857-8

20. Patterson J, Lohr D, Briscoe C, et al: Calcified renal masses. Urology 1987;29:353-6.

Correspondence: Dr. Matei Andreoiu, Department of Urology, University of Indiana, Indianapolis, IN; fax 317-274-3763; mateiandreoiu@hotmail.com 